\title{
Speciation of the Coagulase Negative Staphylococci Isolated from Various Clinical Samples and their Antimicrobial Resistance Pattern at a Tertiary Care Hospital
}

\author{
Authors \\ Mila V.S, Dr.S.Manjusree, Sri.Ashraf Perilacode
}

\begin{abstract}
Background and Objectives: Increased frequencies of CoNS infection is being observed in various hospital setups and a need for better understanding of species distribution and antimicrobial susceptibility pattern prevailing among them has arisen. The rising incidence of bacteraemia along with the long term use of indwelling prosthetic devices is of great concern and demands further research. The study is done to speciate the Coagulase negative Staphylococci isolated from various clinical samples and to reveal the antimicrobial susceptibility pattern among them.

Method: The present study was conducted in the Department Of Microbiology and Department of Medical Laboratory Technology, Government Medical College Thiruvananthapuram. A total of 52 strains of Coagulase negative Staphylococci isolated as a sole agent from various clinical samples were included in the study. The speciation of CoNS was done based on the biochemical reactions.

Results \& Conclusion: Out of 52 sample, $61.5 \%$ is male population and most of the samples were exudates and $27 \%$ of the patients were coming under the working age group. Staphylococcus epidermidis is recognized as the predominant species (58\% of the total isolates). $19.2 \%$ were Methicillin resistant CoNS (MR-CoNS). $44.2 \%$ of all isolates shows induced Clindamycin resistance.

Keywords: CoNS, MR CoNS.
\end{abstract}

\section{Introduction}

Coagulase negative staphylococci (CoNS) are ubiquitously present on skin and were considered as laboratory contaminants and non-pathogenic commensals with relatively low virulence till recently. But now, the trend has changed and CoNS have emerged as one of the most important opportunistic pathogen. Since 1950, cases of CoNS associated infections have been reported with increasing frequencies.

These normal skin inhabitants turn out to be pathogenic when they gain entry into body which may result in CSF shunt infection, prosthetic valve infection, prosthetic joint infection, vascular graft infection etc. The other infections associated with CoNS are eye \& ear infection, skin abscess, infections associated with IV cannulae, peritonitis (in patients receiving peritoneal dialysis). One particular species (Staphylococcus saprophyticus) is associated with UTI in young sexually active females.

The predisposing factors for infections with CoNS are immunosuppression (cancer, renal transplant cases), breaches in natural mucocutaneous barriers, prior exposure to antibiotics and most frequently the presence of an indwelling device. 


\section{JMSCR Vol||05||Issue||03||Page 19063-19068||March}

Device related infections are mainly due to their ability to adhere onto the polymer surfaces and subsequent Biofilm production. The Biofilm protect them from the antibiotics administered and also from the patient s own immune system.

According to National Nosocomial Infection Surveillance System (NNIS, 2001), there is a widespread occurrence of Methicillin resistant CoNS. Increased frequencies of CoNS infection is being observed in various hospital setups and a need for better understanding of species distribution and antimicrobial susceptibility pattern prevailing among them has arisen. The rising incidence of Bactaeremia along with the long term use of indwelling prosthetic devices is of great concern and demands further research.

\section{Methodology}

A cross sectional study was done in the Central Microbiology laboratory, Department of MLT, Government Medical college Hospital, Thiruvananthapuram. A total of 52 strains of Coagulase negative Staphylococci isolated as a sole agent from various clinical samples were included in the study.. The study was approved by Institutional Human Ethics Committee and Institutional Research Committee. The speciation of CoNS was done based on the following test procedures. Tube coagulase test. Slide coagulase test (Clumping factor), PYR Broth hydrolysis test, Novobiocin $(5 \mu \mathrm{gm})$ sensitivity test, Ornithine decarboxylase test, Alkaline Phosphatase test,Polymyxin B (300U) sensitivity test,VogesPrausker test, Fermentation of Trehalose, Mannitol

\section{Results}

Table 1: Sex Distribution of Positive Isolates

\begin{tabular}{|l|c|c|}
\hline Gender & Frequency & Percentage \\
\hline Male & 32 & $61.5 \%$ \\
\hline Female & 20 & $38.5 \%$ \\
\hline
\end{tabular}

Table 2: Age Distribution of Positive Isolates

\begin{tabular}{|l|c|c|}
\hline $\begin{array}{l}\text { Age } \\
\text { in years) }\end{array}$ & Frequency & Percentage (\%) \\
\hline $10-19$ & 4 & 7.7 \\
\hline $20-29$ & 6 & 11.5 \\
\hline $30-39$ & 14 & 27 \\
\hline $40-49$ & 6 & 11.5 \\
\hline $50-59$ & 6 & 11.5 \\
\hline $60-69$ & 11 & 21 \\
\hline $70-79$ & 3 & 5.7 \\
\hline$>80$ & 2 & 3.7 \\
\hline
\end{tabular}

Graph 1: Age Distribution of Positive Isolates

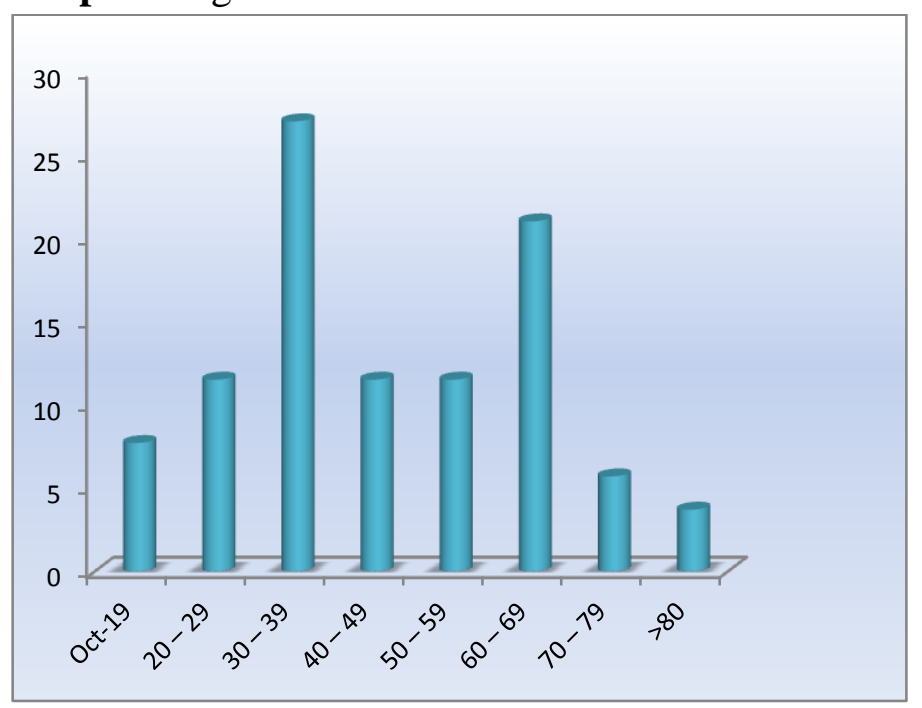

Table 3Specimen Distribution of Positive Isolates

\begin{tabular}{|l|c|c|}
\hline Specimen & Frequency & Percentage \\
\hline Blood & 17 & 32.7 \\
\hline CSF & 1 & 1.9 \\
\hline Exudates & 30 & 57.7 \\
\hline Tissue & 2 & 3.8 \\
\hline Miscellaneous & 2 & 3.8 \\
\hline
\end{tabular}

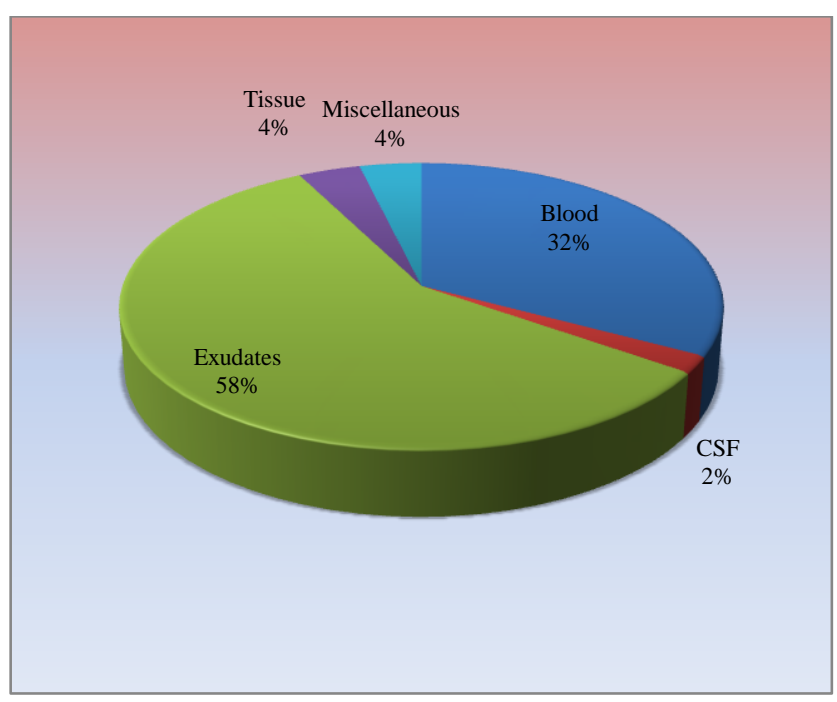

Graph 2 showing specimen distribution 
Table 4: Species Distribution of CoNS

\begin{tabular}{|l|c|c|}
\hline Species & Frequency & Percentage \% \\
\hline S. epidermidis & 30 & 58 \\
\hline S. lugdunensis & 14 & 27 \\
\hline S. haemolyticus & 8 & 15 \\
\hline
\end{tabular}

Table 5: S.Epidermidis - Specimen Distribution

\begin{tabular}{|l|c|c|}
\hline Specimen & Frequency & Percentage (\%) \\
\hline Blood & 11 & 36.7 \\
\hline CSF & 1 & 3.3 \\
\hline Exudates & 17 & 56.7 \\
\hline Tissue & 1 & 3.3 \\
\hline Miscellaneous & - & 0 \\
\hline
\end{tabular}

Table 6: S. lugdunensis - Specimen Distribution

\begin{tabular}{|l|c|c|}
\hline Specimen & Frequency & Percentage (\%) \\
\hline Blood & 7 & 50 \\
\hline CSF & - & 0 \\
\hline Exudates & 5 & 35.8 \\
\hline Tissue & 1 & 7.1 \\
\hline Miscellaneous & 1 & 7.1 \\
\hline
\end{tabular}

\section{Antibiotic Susceptibility Pattern}

Antibiotic susceptibility testing was performed by disc diffusion method as per the Clinical Laboratory Standard Institute (CLSI) recommenddations. Among the beta lactams, maximum resistance was observed against Penicillin $(98.08 \% ; \mathrm{n}=51))$ and resistance to Cefoxitin was seen in $19.2 \%(\mathrm{n}=10)$ of the isolates. All the studied isolates were susceptible to Vancomycin.

Table 7: Antibiotic Susceptibility pattern of Isolates

\begin{tabular}{|l|c|c|c|c|}
\hline \multirow{2}{*}{ Antibiotic } & \multicolumn{2}{|c|}{ Sensitive } & \multicolumn{2}{c|}{ Resistant } \\
\cline { 2 - 5 } & $\begin{array}{c}\text { Frequenc } \\
\mathrm{y}\end{array}$ & $\begin{array}{c}\text { Percentag } \\
\mathrm{e}\end{array}$ & $\begin{array}{c}\text { Frequenc } \\
\mathrm{y}\end{array}$ & $\begin{array}{l}\text { Percenta } \\
\mathrm{e}\end{array}$ \\
\hline Penicillin & 1 & 1.92 & 51 & 98.08 \\
\hline Gentamicin & 26 & 50 & 26 & 50 \\
\hline $\begin{array}{l}\text { Cephalospori } \\
\mathrm{n}\end{array}$ & 27 & 52 & 25 & 48 \\
$1^{\text {st }}$ Generation & & & & \\
\hline Erythromycin & 23 & 44.2 & 29 & 55.7 \\
\hline Amikacin & 47 & 90.4 & 5 & 9.6 \\
\hline Vancomycin & 52 & 100 & 0 & 0 \\
\hline Cefoxitin & 42 & 80.8 & 10 & 19.2 \\
\hline Clindamycin & 43 & 82.6 & 9 & 17.3 \\
\hline
\end{tabular}

Table 8: Antibiotic susceptibility pattern of $S$. epidermidis

\begin{tabular}{|l|c|c|c|c|}
\hline \multirow{2}{*}{ Antibiotic } & \multicolumn{2}{|c|}{ Sensitive } & \multicolumn{2}{c|}{ Resistant } \\
\cline { 2 - 5 } & $\begin{array}{c}\text { Frequenc } \\
\mathrm{y}\end{array}$ & $\begin{array}{c}\text { Percentag } \\
\mathrm{e}\end{array}$ & $\begin{array}{c}\text { Frequenc } \\
\mathrm{y}\end{array}$ & $\begin{array}{c}\text { Percentag } \\
\mathrm{e}\end{array}$ \\
\hline Penicillin & 1 & 3.3 & 29 & 96.6 \\
\hline Gentamicin & 17 & 57 & 13 & 43 \\
\hline $\begin{array}{l}\text { Cephalospori } \\
\mathrm{n}\end{array}$ & 18 & 60 & 12 & 40 \\
$1^{\text {st }}$ generation & & & & 57 \\
\hline $\begin{array}{l}\text { Erythromyci } \\
\mathrm{n}\end{array}$ & 13 & 43 & 17 & 5.6 \\
\hline Amikacin & 28 & 93.4 & 2 & 0 \\
\hline Vancomycin & 30 & 100 & 0 & 20 \\
\hline Cefoxitin & 24 & 80 & 6 & 16.6 \\
\hline Clindamycin & 25 & 83.4 & 5 & \\
\hline
\end{tabular}

Graph 3: Antibiotic susceptibility pattern of $S$. epidermidis

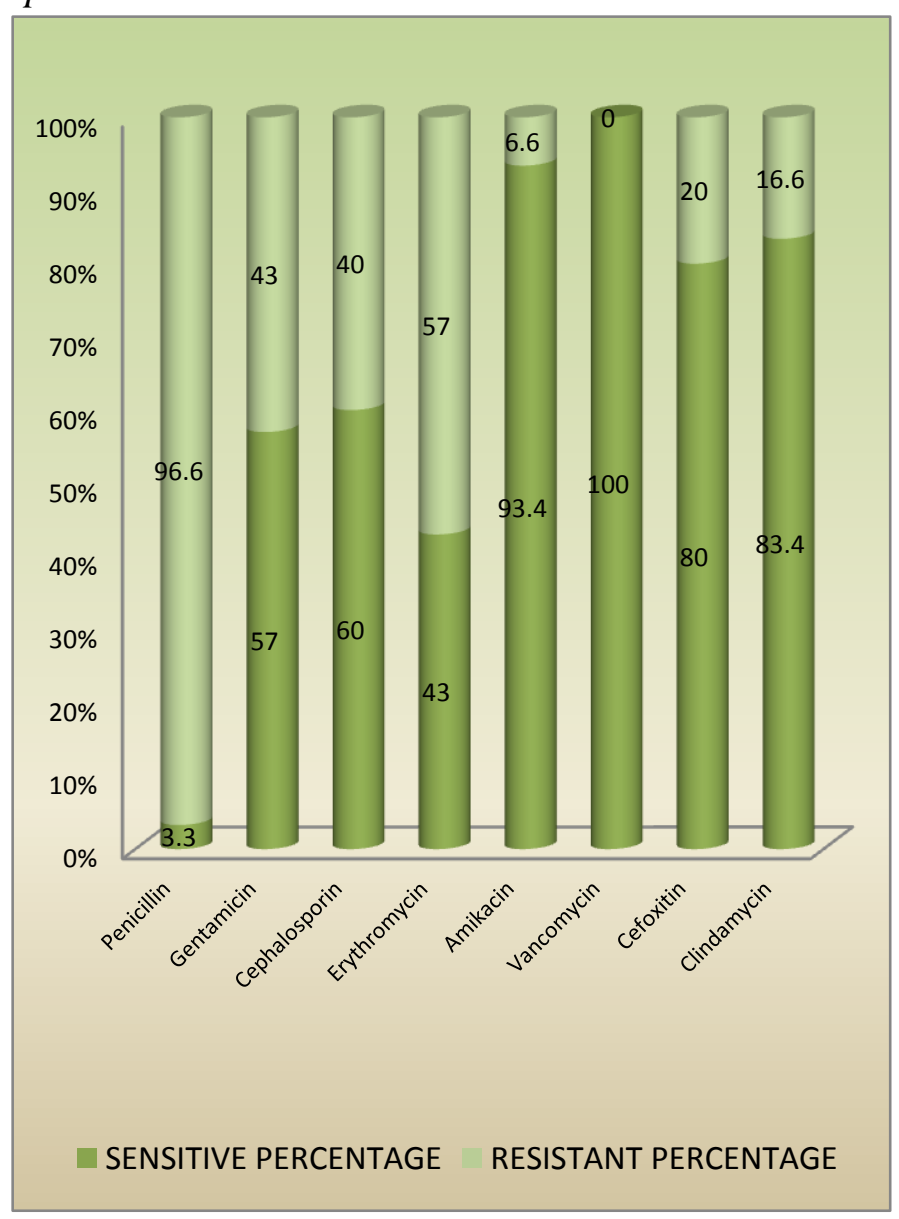


Table 9: Methicillin Resistance in CoNS

\begin{tabular}{|l|c|c|c|}
\hline Species & S.epidermidis & S. lugdunensis & S. haemolyticus \\
\hline Frequency of Isolate & 30 & 14 & 8 \\
\hline Frequency of MR Cons & 6 & 3 & 1 \\
\hline Percentage & 20 & 21 & 12.5 \\
\hline
\end{tabular}

Table 10: Macrolide Resistance in CoNS

\begin{tabular}{|l|c|c|c|c|c|c|}
\hline & \multicolumn{2}{|c|}{ S.epidermidis } & \multicolumn{2}{c|}{ S.lugdunensis } & \multicolumn{2}{c|}{ S. haemolyticus } \\
\cline { 2 - 7 } & Frequency & Percentage & Frequency & Percentage & Frequency & Percentage \\
\hline $\begin{array}{l}\text { iMLS } \\
\text { PHENOTYPE(23) }\end{array}$ & 14 & $61 \%$ & 4 & $18 \%$ & 5 & $21 \%$ \\
\hline $\begin{array}{l}\text { cMLS } \\
\text { PHENOTYPE(6) }\end{array}$ & 3 & $50 \%$ & 3 & $50 \%$ & - & $0 \%$ \\
\hline
\end{tabular}

\section{Discussion}

Among the 52 isolates of CoNS, most of them were from exudates followed by blood, tissue, catheter tips and CSF $(57.7 \%, 32.7 \%, 3.8 \%$, $3.8 \%, 1.9 \%$ respectively). Majority of the patients were male and coming under the working age group of $30-39$.

Staphylococcus epidermidis was recognised as the predominant species (58\% of the total isolates). Goyal $\mathrm{R}$ et al., Sheik et al, have documented similar findings with $41 \%$ and $46 \%$ of isolation rates respectively ${ }^{(1,2,)}$. Senger et al documented a large proportion of of Staphylococcus epidermidis (68\% of the total CoNS isolates) in their study ${ }^{(3)}$. The second most common isolate in our study was $S$ lugdunensis accounting for $27 \%$ of the total isolates. The third most common organism isolated was Shaemolyticus (15\%).

In the present study, majority of the isolates are resistant to Penicillin (98\%) followed by Erythromycin (55\%), Gentamicin (50\%) Cephalosporin (48\%), Cefoxitin (19.2\%) and Clindamycin (17\%), Amikacin (9.6\%) Vancomycin $(100 \%)$ Methicillin resistance( MR CoNS ) (19.2\%) was shown by 10 isolates and all are sensitive to Vancomycin.

Among the macrolide resistant Staphylococcus epidermidis strains, the $\mathrm{CMLS}_{\mathrm{B}}$ phenotype and $\mathrm{iMLS}_{\mathrm{B}}$ phenotype were demonstrated in $10 \%$ and $47 \%$ of the isolates respectively. Among $S$ haemolyticus isolates, none of them reported as $\mathrm{CMLS}_{\mathrm{B}}$ phenotype, where as $\mathrm{iMLS}_{\mathrm{B}}$ phenotype was appeared in $62.5 \%$ of the isolates. Similarly
Gheradi et al reported $\mathrm{MS}_{\mathrm{B}}$ phenotype in $38 \%$ of isolates of $S$ epidermidis and $80 \%$ of isolates of $S$ haemolyticus and $\mathrm{cMLS}_{\mathrm{B}}$ phenotype was observed only in $28.5 \%$ of isolates of $S$ epidermidis. Similarly, Brzychczy-Wloch M et al., who researched the CoNS isolated from invasive infection in very low birth neonates, reported a higher percentage of $\mathrm{MS}_{\mathrm{B}}$ phenotype among $S$ haemolyticus strains (82\%). The study documented $43 \%$ and $40 \%$ of $\mathrm{cMLS}_{\mathrm{B}}$ and $\mathrm{MS}_{\mathrm{B}}$ phenotypes among $S$ epidermidis respectively ${ }^{(4)}$. Consistent with the previous reports, Methicillin resistance and multidrug resistance were found to be high among the studied isolates. $19.2 \%$ of the studied isolates showed Methicillin resistance which is in accordance with the previous reports from different countries including India.

The methicillin resistant isolates were found to be multi drug resistant. $20 \%$ and, $21 \%$ of methicillin resistance was observed in the isolates of $S$ epidermidis and $S$. lugdunensis respectively. In this study, methicillin resistance was predominantly observed in $S$ epidermidis followed by $S$ lugdunensis.

Higher rates of Methicillin resistance have been reported from different countries in a study by Koksal et al., ${ }^{(5)}$ Khan et al., ${ }^{61)}$ and Shan M U ${ }^{(7)}$ et al., with $67.5 \%, 93 \%$, and $40 \%$ resistance rates respectively.. The present study shows $100 \%$ sensitivity to Vancomycin which is similar to studies done by Khadri ${ }^{(8)}$, Rajaduraipandi ${ }^{(9)}$, Anuprabha ${ }^{(10)}$. 
S. epidermidis was isolated from CSF sample of a 32 year old male patient in Neurosurgery ICU, with post hypothalamic glioma excision. The CSF sample was taken from peritoneal ventricular shunt. The patient was afebrile with and total WBC count was 12000. This isolate was only sensitive to Vancomycin and Clindamycin. Biofilm production was positive for this isolate by tube method. S. lugdunensis was isolated from a an infected implant, which was removed by surgery and was negative for bio- film production. It was sensitive for all drugs except Penicillin, Erythromycin, Clindamycin. S. epidermidis was isolated from a case of carcinoma of breast with multiple ulcers in stomach wall and it was resistant to Penicillin and Gentamicin.

The first reports of Vancomycin resistance and Linezolid resistance was documented among CoNS. which suggests that there is an alarming threat of the transmission of the resistance to other virulent pathogens such as $S$ aureus.

CoNS have been considered as normal skin inhabitants with relatively low virulence. But they turn out to be pathogenic once entered into the body and are able to cause a variety of infections in humans. Moreover, by acting as a reservoir of resistant genes, they promote the development of antibiotic resistance in other virulent pathogens. The hospital strains are mostly multidrug resistant and thus limits the therapeutic options in the treatment of CoNS related infections. For these reasons, CoNS demand more recognition as pathogens and must be addressed earnestly. Increased frequencies of CoNS infection is being observed in various hospital setups and a need for differentiating the pathogenic strains of CoNS from the non-pathogenic one has arisen.

\section{References}

1. Goyal R, Singh NP, Kumar A, Kaur I, Singh M, Sunita N, et al.,. Simple and economical method for speciation and resistotyping of clinically significant coagulase negative staphylococci. Indian J Med Microbiol. 2006;24(3):201.
2. Ahmad Farajzadeh Sheikh. Identification and determination of coagulase-negative Staphylococci species and antimicrobial susceptibility pattern of isolates from clinical specimens. Afr J Microbiol Res. 2012 Feb 29;6 (8).

3. Senger SS, Saccozza ME, Yce A. Compatibility of Pulsed-Field Gel Electrophoresis Findings and Clinical Criteria Commonly Used to Distinguish Between True Coagulase-Negative Staphylococcal Bacteremia and Contamination. Infect Control Hosp Epidemiol. 2007;28: 992-996.

4. Brzychczy-Wloch M, BorszewskaKornacka M, Gulczynska E, WojkowskaMach J, Sulik M, Grzebyk M, et al.,. Prevalence of antibiotic resistance in multi-drug resistant coagulase-negative staphylococci isolated from invasive infection in very low birth weight neonates in two Polish NICUs. Ann Clin Microbiol Antimicrob. 2013;12:41.

5. Koksal F, Yasar H, Samasti M. Antibiotic resistance patterns of coagulase-negative Staphylococcus strains isolated from blood cultures of septicemic patients in Turkey. Microbiol Res. 2009;164(4):404-10.

6. Khan MM, Faiz A, Ashshi AM. Clinically significant Coagulase Negative Staphylococci and their antibiotic resistance pattern in a tertiary care hospital. J Pak Med Assoc. 2014;64(10):1171-4.

7. Shah MU, Akram MF, Usman J, Kaleem F. Incidence and Susceptibility Pattern of Methicillin Resistant Coagulase-negative Staphylococci Isolated From a Tertiary Care Hospital of Pakistan. Jundishapur $\mathbf{J}$ Microbiol [Internet]. 2014 Jan 1 [cited 2016 Apr 29];7(1).

8. Khadri H, Alzohairy M. Prevalence and antibiotic susceptibility pattern of methicillin-resistant and coagulasenegative staphylococci in a tertiary care 
hospital in India. Int $\mathrm{J}$ Med Med Sci. 2010;2(4):116-20.

9. Rajaduraipandi K, Mani KR, Panneerselvam K, Mani M, Bhaskar M, Manikandan $\mathrm{P}$, et al.,. Prevalence and antimicrobial susceptibility pattern of methicillin resistant Staphylococcus aureus: A multicentre study. Indian J Med Microbiol. 2006;24(1):34.

10. Anuprabha, S, Sen.M.R, Nath,G, Sharma, B.M. Gulati, A.K. Prevalence of Methicillin resistant Staphylococcus aureus at a tertiary referral hospital in East Uttar Pradesh. Indian J Med Microbiol. 2003; 21:49-51. 